Volume 2 Nomor 1 Edisi Juni 2013

ISSN 2354-7200
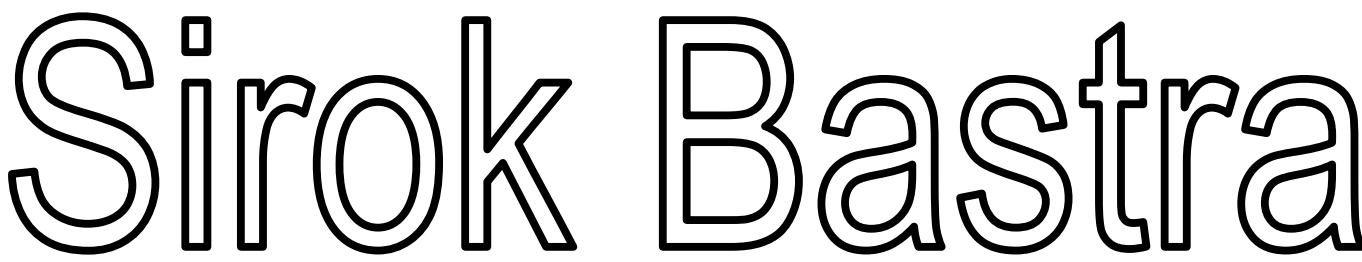

JURNAL ILMIAH KEBAHASAAN DAN KESASTRAAN

\begin{tabular}{|c|c|l|c|c|c|}
\hline $\begin{array}{c}\text { Sirok Bastra } \\
\text { Jurnal Kebahasaan dan } \\
\text { Kesastraan }\end{array}$ & Volume 2 & Nomor 1 & $\begin{array}{c}\text { Hlm. } \\
1-120\end{array}$ & $\begin{array}{c}\text { Pangkalpinang, } \\
\text { Juni 2013 }\end{array}$ & $\begin{array}{c}\text { ISSN } \\
2354-7200\end{array}$ \\
\hline
\end{tabular}

KANTOR BAHASA PROUINSI BANGKA BELITUNG 


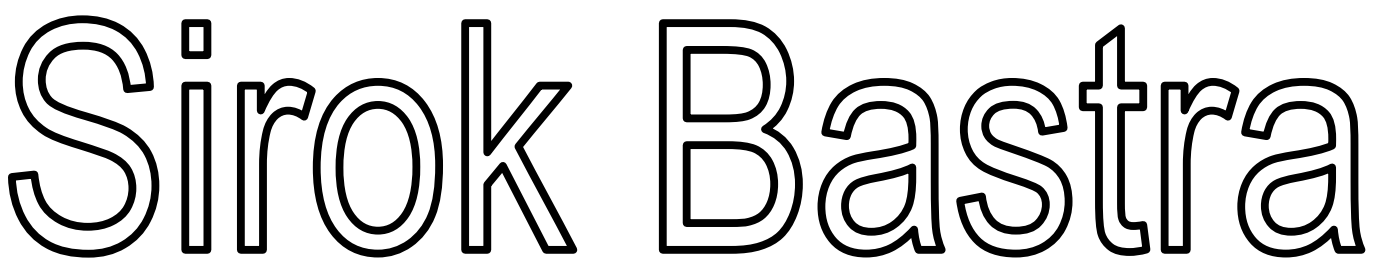

\section{JURNAL ILMIAH KEBAHASAAN DAN KESASTRAAN}

Jurnal ini merupakan wadah informasi mengenai kebahasan, kesastraan, dan pengajarannya yang memuat hasil penelitian, studi kepustakaan, dan tulisan ilmiah bidang kebahasan dan kesastraan serta pengajarannya. Sirok Bastra terbit dua kali setahun, yakni Juni dan Desember, serta terbit sejak Juni 2013.

\section{Penanggung Jawab}

Kepala Kantor Bahasa Provinsi Bangka Belitung Drs. Umar Solikhan, M.Hum.

\section{Mitra Bestari}

Prof. Dr. Agus Nuryatin, M.Hum. (Bidang Sastra dan Pengajarannya)

Prof. Amrin Saragih, Ph.D., M.A. (Bidang Bahasa dan Pengajarannya)

Dr. Felicia Nuradi Utorodewo, M.Hum. (Bidang Bahasa dan Pengajarannya)

Dr. Pujiharto, M.Hum. (Bidang Sastra dan Pengajarannya)

\section{Pemimpin Redaksi}

Rahmat Muhidin, S.S.

\section{Penyunting}

Prima Hariyanto, S.Hum.

\section{Perancang Sampul}

Feri Pristiawan, S.S.

\section{Kesekretariatan}

Khaliffitriansyah, S.Pd.

Dea Letriana Cesaria, S.Hum.

Lia Aprilina, S.Pd.

Andrian Priyatno, A.Md.

Elzam

\section{Alamat Redaksi dan Penerbit}

Kantor Bahasa Provinsi Bangka Belitung

Ruko Permata 7, Jalan Solihin G.P. Km 4, Kota Pangkalpinang, Prov. Kepulauan Bangka Belitung

Telp./Faks.: 0717-438455, Pos-el: sirokbastra@gmail.com

Pemuatan suatu tulisan dalam jurnal ini tidak berarti redaksi menyetujui isi tulisan tersebut. Isi tulisan menjadi tanggung jawab penulis. Tulisan telah ditinjau dan diulas oleh mitra bestari. Setiap karangan dalam jurnal ini dapat diperbanyak setelah mendapat izin tertulis dari penulis, redaksi, dan penerbit. 


\section{PENGANTAR}

Puji syukur ke hadirat Pemilik dan Pencipta semesta ini yang memiliki kuasa atas diri-Nya sendiri. Dialah Tuhan Yang Maha Esa yang telah memberikan rahmat dan hidayah-Nya sehingga Volume 2 Nomor 1 Jurnal Sirok Bastra Tahun 2014 dapat terbit tepat pada waktunya.

Pada edisi ini, dimuat sepuluh tulisan, yakni enam tulisan kesastraan dan empat tulisan kebahasaan. Dalam kajiannya, Anita Rima Dewi melihat kedudukan perempuan Jawa dalam keluarga — tergambar dalam novel Hati Sinden karya Dwi Rahyuningsih — dilihat dari perspektif gender. Berdasarkan penelitian, ditemukan bahwa diskriminasi gender seperti marginalisasi, stereotipe, dan subordinasi melahirkan berbagai kekerasan, yakni ekonomi, fisik, psikis, dan seksual.

Dalam kajiannya, Sarman membahas mitos buluh perindu dalam cerita rakyat Bangka. Mitos Bukit Tambun Tulang memuat struktur geografis yang menunjukkan adanya pola perjalanan hidup tokoh dalam mempertahankan hidup; struktur tekno-ekonomi yang menunjukkan adanya sistem mata pencaharian orang Bangka, antara lain berburu dan berkebun; struktur sosiologis yang menunjukan adanya hubungan sosial antara sesama manusia; dan struktur kosmologis yang menunjukkan adanya keterkaitan antara dunia nyata dan dunia gaib.

Dalam penelitiannya, Iis Afriatiningsih membahas sosok perempuan dalam karya sastra Indonesia yang diwakili oleh Nyai Ontosoroh, Pariyem, Clara yang menghadapi banyak tantangan dalam hidupnya. Hasil analisis menunjukkan bahwa sosok perempuan memiliki sikap, seperti memperjuangkan hidupnya (tergambar dalam tokoh Nyai Ontosoroh), pasrah dengan nasibnya (tergambar dalam tokoh Pariyem), dan nasibnya ada di tangan rakyat kecil (tergambar dalam tokoh Clara). Perjuangan perempuan tersebut berkaitan dengan kritik formalisme, strukturalisme, posstrukturalisme, dan posmoderenisme.

Dalam kajiannya, Asep Supriadi mengaplikasikan teori takmilah yang digagas oleh seorang pakar sastra Melayu bernama Shafie Abu Bakar pada puisi "Idul Fitri" karya Sutardji Calzoum Bachri. Hasil kajian menunjukkan bahwa puisi tersebut menggambarkan nilai-nilai keislaman dengan dimensi sufistik. Puisi itu menggambarkan perenungan eksistensi diri pada Tuhan.

Dalam kajiannya, Ch. Haris Maulana membahas tokoh dan penokohan serta nilai moral dan kekhasan yang ada dalam serial Harry Potter, khususnya seri pertama, Harry Potter dan Batu Bertuah. Nilai moral dan kekhasan yang tersirat dalam serial ini adalah sihir dapat dipelajari dan bukan faktor keturunan, kesetiakawanan, kedisipilinan, kepedulian, dan keingintahuan.

Dalam penelitiannya, Dwi Oktarina menggali aspek hibriditas dan ambivalensi yang terjadi pada tokoh Mata Hari dalam novel Namaku Mata Hari karya Remy Silado. Mata Hari, seorang agen spionase keturunan Belanda-Jawa bekerja pada banyak negara pada saat perang dunia berkecamuk. Selain itu, permainan politik tubuh Mata Hari juga menjadi sebuah hal yang menarik untuk diteliti lebih jauh. Berdasarkan penelitian, didapatkan hasil bahwa ruang-ruang pertemuan antara dua kebudayaan sama sekali tidak bisa dielakkan. Mata Hari sebagai Indo berdarah campuran Belanda-Indonesia tidak dapat melepaskan dirinya dari dua kebudayaan yang melingkupinya, Belanda maupun Indonesia.

Dalam kajiannya, Maria Christa Istiana Kamagi membahas struktur kalimat dan keterbacaan pada buku teks pelajaran bahasa Indonesia. Berdasarkan penelitian, ditemukan kalimat tunggal perluasan subjek, predikat, objek, dan pelengkap, kalimat tunggal perluasan keterangan, kalimat majemuk setara, kalimat majemuk bertingkat, kalimat majemuk bersusun, dan kalimat taklengkap. Selain menjelaskan struktur kalimat yang ada, penelitian ini juga mencoba menganalisis keterbacaan dilihat dari jumlah kata yang digunakan dalam kalimat tersebut. Hasil yang didapat adalah terdapat beberapa kalimat yang masih masuk kategori kalimat sulit dan sangat sulit dipahami.

Dalam kajiannya, Achril Zalmansyah membahas hasil Uji Kemahiran Berbahasa Indonesia (UKBI) guru dan siswa SMP di Kabupaten Lampung Utara. Data yang diperoleh menunjukkan bahwa sebagian besar peserta memperoleh nilai antara 300-400 yang berarti cukup baik. Dengan demikian, dapat dikatakan bahwa UKBI 
merupakan alat uji yang dapat digunakan untuk mengukur penguasaan bahasa Indonesia seorang guru serta penggunaan bahasa Indonesia yang baik dan benar oleh siswa.

Dalam kajiannya, Prima Hariyanto membahas kata berinfiks -er- dalam bahasa Indonesia. Korpus data penelitian ini adalah Kamus Besar Bahasa Indonesia Edisi Ketiga. Berdasarkan penelitian yang dilakukan, ditemukan 62 kata berinfiks -er- yang terdiri dari 14 jenis kelompok makna. Selain memaparkan kata berinfiks yang ada, penelitian ini juga mencoba memaparkan metode pendefinisian lema kata berinfiks yang -er-bermakna 'sama dengan bentuk dasarnya' dalam Kamus Besar Bahasa Indonesia.

Dalam penelitiannya, Hotnida Novita Sary mengkaji perbedaan bentuk verba yang terdapat dalam bahasa Melayu Tinggi dan bahasa Melayu Rendah yang terdapat dalam Injil Matius terjemahan Klinkert. Peneliti mengunduh data dari laman sabda.org. Kedua versi Injil Matius ini kemudian dibandingkan dan dicatat satu ayat dengan ayat yang sama. Hasil pencatatan inilah yang dianalisis. Hasil yang didapatkan dari penelitian ini adalah ragam bahasa Melayu Tinggi cenderung menggunakan bentuk berimbuhan, sedangkan bahasa Melayu Rendah cenderung menggunakan bentuk dasar.

Kami mengucapkan terima kasih kepada para penulis yang telah bersedia menerbitkan karya mereka pada edisi ini. Para penulis merupakan peneliti, pakar, dosen, siswa, dan mahasiswa dari berbagai sekolah, perguruan tinggi, dan instansi. Terima kasih juga kami sampaikan kepada para mitra bestari kami yang telah memberi ulasan terhadap tulisan-tulisan yang masuk ke redaksi.

Demi memenuhi keberagaman isi dan penulis, Sirok Bastra membuka kesempatan bagi para peneliti dan penulis menyampaikan hasil penelitian dan pemikiran mutakhir dalam bidang kebahasaan, kesastraan, dan pengajarannya.

Pangkalpinang, Juni 2014

Tim Redaksi 


\section{UCAPAN TERIMA KASIH UNTUK MITRA BESTARI}

Redaksi Sirok Bastra mengucapkan terima kasih kepada para mitra bestari yang telah meninjau, menimbang, dan mengulas makalah-makalah yang diterbitkan dalam Sirok Bastra Volume 2 Nomor 1, edisi Juni 2014, yakni

Prof. Dr. Agus Nuryatin, M.Hum.

Bidang Sastra dan Pengajarannya

Universitas Negeri Semarang

Semarang, Jawa Tengah

Prof. Amrin Saragih, Ph.D., M.A.

Bidang Bahasa dan Pengajarannya

Universitas Negeri Medan

Medan, Sumatra Utara

Dr. Felicia Nuradi Utorodewo, M.Hum.

Bidang Bahasa dan Pengajarannya

Universitas Indonesia

Depok, Jawa Barat

\section{Dr. Pujiharto, M.Hum.}

Bidang Sastra dan Pengajarannya

Universitas Gadjah Mada

Yogyakarta, Daerah Istimewa Yogyakarta 


\section{DAFTAR ISI}

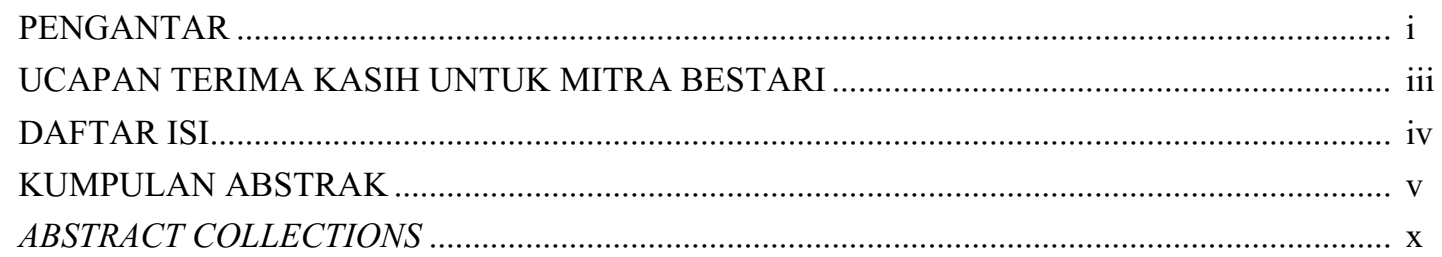

KEDUDUKAN PEREMPUAN JAWA DALAM NOVEL HATI SINDEN KARYA DWI RAHYUNINGSIH DILIHAT DARI PERSPEKTIF GENDER

(The Position of Javanese Women Based on Gender Perspective in Hati Sinden, a Novel by Dwi Rahyuningsih)

Anita Rima Dewi $1-15$

MITOS DALAM CERITA “BUKIT TAMBUN TULANG”

(Myth in "Bukit Tambun Tulang" Story)

Sarman. $17-24$

SOSOK PEREMPUAN DARI ZAMAN KE ZAMAN DALAM KARYA SASTRA INDONESIA: STUDI KASUS TOKOH NYAI ONTOSOROH, PARIYEM, DAN CLARA (Figure of Women from Time to Time in Indonesian Literary Works: A Case Study of Nyai Ontosoroh, Pariyem, and Clara)

Iis Afriatiningsih $25-33$

MEMAHAMI PUISI "IDUL FITRI" DENGAN TEORI TAKMILAH

(Understanding the Poetry "Idul Fitri” by Using Theory of Takmilah)

Asep Supriadi $35-44$

NILAI DAN KEKHASAN SERIAL HARRY POTTER (KAJIAN HARRY POTTER 1: HARRY POTTER DAN BATU BERTUAH)

(Value and Uniqueness of Harry Potter Series [A Study of Harry Potter 1: Harry Potter and The Sorcerers Stone])

Ch. Haris Maulana $45-52$

HIBRIDITAS DAN POLITIK TUBUH DALAM NOVEL NAMAKU MATA HARI KARYA REMY SILADO: SEBUAH TINJAUAN POSKOLONIAL

(Hybridity and Body Politic in Namaku Mata Hari, A Novel Written by Remy Silado: A Postcolonial Study)

Dwi Oktarina $53-61$

STRUKTUR DAN KETERBACAAN KALIMAT PADA BUKU TEKS PELAJARAN BAHASA INDONESIA

(Sentence Structure and Readability in Indonesian Textbook)

Maria Christa Istiana Kamagi. $63-78$ 
UJI KEMAHIRAN BERBAHASA INDONESIA (UKBI) BAGI GURU DAN SISWA SEKOLAH MENENGAH PERTAMA SE-LAMPUNG UTARA

(Indonesian Proficiency Test [UKBI] for Teacher and Junior High School Students All Lampung Utara)

Achril Zalmansyah

KATA BERINFIKS -ER- DALAM BAHASA INDONESIA

(-er- Infixes Words in Indonesian)

Prima Hariyanto

$89-103$

PERBEDAAN BENTUK VERBA PADA BAHASA MELAYU TINGGI DAN BAHASA

MELAYU RENDAH: STUDI KASUS INJIL MATIUS TERJEMAHAN KLINKERT

(Verb Form of Differences in Language Malay Malay Language High and Low: Case Study of The Gospel of Matthew Klinkert Translations)

Hotnida Novita Sary .... $105-120$ 
Asep Supriadi: Memahami Puisi "Idul Fitri” dengan Teori Takmilah

\title{
MEMAHAMI PUISI “IDUL FITRI” DENGAN TEORI TAKMILAH
}

\section{Understanding the Poetry "Idul Fitri" by Using Theory of Takmilah}

\author{
Asep Supriadi \\ Balai Bahasa Provinsi Jawa Barat \\ Jalan Sumbawa Nomor 11, Bandung 40113, Telp. 022-92455752 \\ Pos-el: asepsupriadi67@yahoo.co.id
}

(diterima 28 Februari 2014, disetujui 16 Mei 2014, revisi terakhir 28 Mei 2014)

\begin{abstract}
Abstrak
Kajian sastra islami dalam sastra Indonesia dengan menggunakan pendekatan teori sastra Islam belum banyak dilakukan. Penulis berpendapat bahwa teori-teori sastra Islam Melayu (Malaysia) dapat diaplikasikan untuk mengkaji sastra Islam Indonesia. Salah satunya adalah teori takmilah yang digagas oleh seorang pakar sastra Melayu bernama Shafie Abu Bakar. Kajian ini mengaplikasikan teori tersebut pada puisi "Idul Fitri" karya Sutardji Calzoum Bachri. Hasil kajian menunjukkan bahwa puisi tersebut menggambarkan nilai-nilai keislaman dengan dimensi sufistik. Puisi itu menggambarkan perenungan eksistensi diri pada Tuhan. Penggambaran itu diperkuat dengan adanya kata-kata cahaya, cinta, salat, zikir, dan taubat dalam puisi tersebut. Kata-kata tersebut dalam istilah takmilah atau tasawuf disebut tafakur dan muhasabah. Dengan melakukan tafakur dan muhasabah, seorang sufi mengharapkan datangnya cahaya Tuhan. Dalam teori takmilah cahaya itu disebut nur ilahiah, artinya cahaya yang datang dari Tuhan. Seperti tampak dalam larik keenam pada bait keempat, "Kini biarkan aku menenggak arak cahayaMu".
\end{abstract}

Kata kunci: puisi, tasawuf, takmilah

\begin{abstract}
Islamic literature studies in Indonesian literature using theory of islamic literature aproach rarely has been done. The writer thinks that the theories of (Malaysian) Melayunese islamic literatures can be aplied to study Indonesian islamic literature. One of them is takmilah theory proposed by an expert of Melayunese literature named Shafie Abu Bakar. This study aplied the theory to the poem "Idul Fitri", written by Sutardji Calzoum Bachri. The result shows that the poem describes islamic values with sufistic dimension. The poem describes contemplation of self existence to the God. The description is strengthened with the words light, love, salat, zikir, and repent in the poem. The words in takmilah's terminolgy or tasawuf are tafakur and muhasabah. By doing tafakur and muhasabah, a sufist expect the coming of God's light. In takmilah theory, the light is said nur ilahiah which means the light coming from God. As it appears in the sixth line of the fourth verse, "Now, let me drink arak of Your light."
\end{abstract}

Keywords: poetry, sufism, takmilah

\section{PENDAHULUAN}

\subsection{Latar Belakang}

Beberapa pengarang yang hasil karyanya bersifat islami di antaranya adalah Taufik Ismail, Asma Nadia, Helvi Tiana Rosa, Abidah, Azhari, Ucu Agustian, Amir Hamzah, Hamka, Ali Audah, Mohammad Diponegoro, Motinggo Busye, Kuntowijoyo, M. Fudoli Zaini, A. Mustofa Bisri, A.A. Navis, Djamil Suherman, Abdul Hadi W.M., Mustofa W. Hasyim, Juftazani, Acep Zamzam Noor, Hamdy
Salad, Mathori A. Elwa, Habiburrahman El-Shirazy, dan Sutardji Calzoum Bachri. Dengan munculnya pengarang karya sastra Indonesia yang menghasilkan karya sastra Indonesia yang islami ini, setidaknya karya tersebut telah dijadikan objek kajian sastra bagi kalangan akademisi dan peneliti bidang sastra. Kajian karya sastra islami relevan dengan menggunakan pendekatan teori sastra Islam. Pendekatan teori sastra Islam yang dianggap sesuai dengan karakter sastra Indonesia islami adalah teori sastra Islam dari sastra 
Melayu (Malaysia). Pakar sastra Melayu, yakni Shafie Abu Bakar, telah berhasil menciptakan teori sastra islami yang disebut dengan teori takmilah (Sikana, 2005).

Pengertian sastra Islam menurut Navis (dalam Tasai dan Djamari, 2003:118-119) ialah sastra karena Allah, sastra sebagai ibadah, sastra sebagai amal saleh, sastra sebagai titik tolak, mardhatilah sebagai tujuan, dan amal saleh sebagai alurnya. Jika dirangkumkan, definisi sastra Islam adalah sastra yang melukiskan kebenaran, kesempurnaan, dan keindahan yang mengandung keadaan menurut syariat Islam, yang ditulis oleh sastrawan muslim yang saleh dan memahami teologi Islam serta hasilnya akan membuat orang menjadi ingat kepada Allah yang berfaedah untuk manusia. Dalam menelaahnya, penelaah memahami teologi Islam serta mengenal kehidupan beragama sastrawannya karena sebuah karya sastra tidak dapat dipisahkan dari pengarangnya, seperti halnya salat tidak dapat dipisahkan dari rukunnya.

Menurut Taufik Ismail dalam suatu percakapan di masjid Al-Azhar, Padang, penelaahan akademik memakai teori sastra barat tidak dapat dipakai pada penelaahan sastra Islam. Selain itu, Navis juga berpendapat bahwa karena bersifat sosial, agama Islam menjadi milik bersama. Setiap gagasan atau tafsiran dipandang dengan ukuran yang tetap dan telah menjadi patokan bersama sehingga masyarakat Islam cenderung bersikap konservatif dengan dalil. Lebih baik memelihara yang ada daripada memakai yang baru yang nilainya belum tentu. Oleh sebab itu, tidak mengherankan apabila kalangan sastrawan Islam memberi petunjuk pada gagasan peribadatan yang menuju salat dan melukiskan kebenaran menurut syariat yang telah disahkan oleh jemaah. Setidaknya, pandangan itu menghendaki agar sastra menjadi kreativitas muslim yang eksplisit bagi kepentingan umat Islam dalam beribadat.

Akan tetapi, Abdurahman Wahid mempunyai pandangan yang moderat. Menurutnya, intensitas pengalaman beragama, ekspresinya implisit dan juga eksplisit. Semuanya dapat diekspresikan ke dalam sastra sehingga tak ada salahnya kalau tokoh pelacur pun ditampilkan dalam sastra Islam karena perasaan keagamaan pelacur belum tentu kalah dari perasaan keagamaan seseorang yang melaksanakan salat berjamaah di mesjid.

Menurut Rosa (2003:8), untuk mengenali sastra Islam, baik puisi, cerpen maupun novel, tidak dapat melalaikan pembacanya dari dzikrullah. Ketika membaca, kita akan diingatkan, baik pada ayat-ayat kauliyah maupun kauniyah-Nya. Ada unsur amar makruf nahi mungkar-dengan tanpa menggurui tentunya-ibrah dan hikmah. Ia kerap bercerita tentang cinta, baik cinta pada Allah, Rasul-Nya, perjuangan di jalan-Nya, maupun cinta pada kaum muslimin dan semua makhluk Allah: semua manusia, hewan, tumbuhan, alam raya dan sebagainya. Ciri lainnya, karya sastra Islam tidak akan pernah mendeskripsikan hubungan badani, kemolekan tubuh perempuan atau betapa "indahnya" kemaksiatan secara vulgar dengan mengatasnamakan seni atau aliran sastra apa pun. Ia juga tak membawa kita pada tasyabuh bil kuffar, apalagi jenjang kemusyrikan.

Secara ringkas, dapat dikatakan bahwa sedikitnya ada tiga syarat umum sebuah karya sastra dapat dikatakan sebagai sastra Islam. Pertama, penulisnya adalah seorang muslim yang sadar dan bertanggung jawab akan kesucian agama. Kedua, karya kreatif yang dihasilkan hendaknya sejalan dengan ajaran Islam dan tidak bertentangan dengan syariah. Ketiga, karya itu mempunyai daya tarik universal dan dapat bermanfaat bagi masyarakat mana pun mengingat Islam adalah agama fitrah.

Menurut Bakar (1996:27) sastra Islam adalah karya sastra yang di dalamnya membicarakan falsafah ketauhidan yang bersumber dari Alquran dan hadis nabi yang memancarkan nilai-nilai keislaman. Nilainilai keislaman itu oleh Bakar dituangkan dalam tujuh aspek, yaitu aspek ketuhanan, aspek kerasulan, aspek keislaman, aspek ilmu, aspek estetika, aspek pengarang, dan aspek pembaca. Menurut Bakar, mengkaji sastra Islam harus syumul, yaitu harus bertolak dari falsafah tauhid yang di dalamnya terangkum dalam tujuh aspek tersebut. Sastra Islam harus menjunjung tinggi falsafah ketauhidan, yaitu mengesakan Tuhan dengan bersumber dari Alquran dan hadis nabi yang merupakan keyakinan dan pegangan umat muslim yang harus diperjuangkan, dihayati, dan diamalkan secara terus-menerus. 
Menurut Hanafiah dan Hasan (dalam Santosa, 2004:1) kesusastraan Indonesia lama yang telah mengenal kisah nabi-nabi Kisasul Anbiya atau surat Al-Anbiya. Karya itu juga merupakan contoh wacana sastra keagamaan yang ditulis berdasarkan kitab suci Alquran, kitab suci umat Islam, yang di dalamnya, antara lain terdapat "Kisah Nabi Adam Alaihissalam" dan "Kisah Nabi Nuh Alaihissalam".

Salah satu pengarang yang karyanya menggambarkan sastra islami adalah Sutardji Calzoum Bachri. Sutardji awalnya dalam menulis karya sastra, isinya tidak menggambarkan sastra islami. Hal ini seperti terlihat dalam kumpulan puisinya $O$ (1973), Amuk (1977), dan Kapak (1979). Kemudian ketiga kumpulan puisinya itu dikumpulkan dalam satu judul buku O, Amuk, Kapak yang diterbitkan pada tahun 2002 oleh Yayasan Indonesia dan Majalah Horison. Kumpulan puisi tersebut tidak menggambarkan sastra islami. Baru pada awal 1980an, Sutardji melakukan pengembaraan, pencarian spiritual, dan mendalami tasawuf. Hal ini berpengaruh terhadap puisi-puisinya yang mulai mengaitkan karya sastra dengan nilai-nilai ketuhanan atau transenden. Pada masa itulah, Sutardji mulai berpuisi dengan tema ketuhanan berdimensi islami. Salah satu puisi yang dianggap termasuk puisi berdimensi islami karya Sutardji adalah puisi berjudul "Idul Fitri" terbit dalam Harian Pelita, Sastra Transedental, Rabu, 21 Oktober 1987, halaman V.

\subsection{Tujuan Penelitian}

Penelitian ini bertujuan untuk memahami makna puisi "Idul Fitri" karya Sutardji Calzoum Bachri dengan menggunakan pendekatan teori takmilah.

\subsection{Metode Penelitian}

Metode penelitian yang akan digunakan adalah metode deskriptif. Metode deskriptif digunakan untuk mengungkapkan makna melalui kata-kata yang ada hubungannya dengan fenomena ajaran tasawuf yang dianalisis secara sistematis, faktual, dan akurat dari sampel penelitian, yakni dalam sebuah puisi "Idul Fitri" karya Sutardji Calzoum Bachri. Untuk mengungkapkan makna-makna yang terkandung di dalamnya, puisi tersebut dikaji dengan menggunakan pendekatan teori takmilah yang terdapat dalam buku teori sastra Islam yang berjudul Takmilah: Teori,
Falsafah dan Prinsip. Teori ini ditulis oleh Shafei Abu Bakar yang bukunya diterbikan oleh Dewan Sastera, Kuala Lumpur pada tahun 1996 dan dalam buku Teori dan Kritikan Sastra Malaysia dan Singapura ditulis oleh Mana Sikana yang diterbitkan oleh penerbit Pustaka Karya, Dewan Bahasa dan Pustaka pada tahun 2005.

Sementara itu, dalam penelitian ini juga akan diterapkan teknik studi pustaka. Teknik ini digunakan dalam hal penelusuran makna dalam kata-kata yang terdapat dalam puisi "Idul Fitri" karya Sutardji Calzoum Bachri yang berkaitan dengan ajaran tasawuf.

\section{KERANGKA TEORETIS}

Sastra keagamaan menarik untuk dijadikan objek penelitian karena terdapat kaitan antara karya sastra dan agama. Bentuk sastra seperti itu merupakan hasil perpaduan antara budaya dan nilai-nilai ajaran agama (Santosa dkk, 2004:1). Sastra keagamaan adalah sastra yang mengandung nilai-nilai ajaran agama yang di dalamnya menggambarkan nilai-nilai ajaran Islam.

Pengertian sastra islami sampai saat ini belum menemukan keseragaman. Setiap pakar sastra Islam memberikan definisi yang berbeda. Meskipun demikian, pada intinya pengertian sastra Islam itu merunut dari nilai-nilai keislaman. Misalnya, menurut Bakar (1996:27) sastra Islam adalah karya sastra yang di dalamnya membicarakan falsafah ketauhidan yang bersumber dari nilai-nilai ajaran Islam. Menurut Sikana, nilai-nilai ajaran Islam ialah ukuran sikap dan perilaku berdasarkan pada syariat Islam yang bersumber dari Alquran dan hadis nabi (2005:93).

Teori takmilah dibangun oleh tujuh aspek yang bermuara pada kata kamal (sempurna). Ketujuh aspek teori takmilah adalah (1) aspek ketuhanan (kamal) yang di dalamnya mengandung unsur keimanan, sifat Allah, syariat, tarikat, hakikat, dan makrifat; (2) aspek kerasulan (kamil) yang di dalamnya mengandung unsur keteladanan Rasul dan hadis nabi; (3) aspek keislaman (akmal) yang di dalamnya mengandung unsur syariat dan rukun Islam; (4) aspek keilmuan (takamul) yang di dalamnya mengandung unsur akal, rasional, dan ilmiah; (5) aspek estetika (takmilah) yang di dalamnya mengandung unsur lahiriah (bentuk, struktur, dan bahasa) dan makna (tema, amanat, dan pandangan); (6) aspek pengarang 
(istikmal), yang di dalamnya mengandung unsur keislaman dan dakwah; (7) aspek pembaca (kamil) yang di dalamnya mengandung unsur manfaat (fungsi) dan nilai-nilai (Sikana, 2005).

Menurut teori takmilah (Bakar, 1996 dan Sikana, 2005), dalam memahami karya sastra tidak dapat dilepaskan dari aspek ketuhanan. Aspek ketuhanan ini bertolak dari konsep bahwa keindahan merupakan manifestasi kesempurnaan Allah. Segala sesuatu harus dilakukan demi Allah yang Mahasempurna. Aspek ketuhanan ini bermuara pada sifat Allah, yaitu sifat kamal, jamal, dan jalal. Selain itu, yang termasuk aspek ketuhanan adalah rukun iman, yaitu percaya terhadap adanya Allah, percaya terhadap adanya malaikat Allah, percaya terhadap adanya kitab-kitab Allah yang diturunkan kepada para nabi, percaya kepada adanya rasul, percaya terhadap adanya hari kiamat, dan percaya terhadap adanya takdir.

Dengan demikian, intisari dari aspek ketuhanan berakar kepada akidah. Akidah termasuk syariat, tarikat, hakikat, dan makrifat. Syariat berupa amalanamalan yang diwajibkan dalam agama, yang dikenal dengan ibadah. Sumbernya berasal dari Alquran dan hadis nabi. Oleh karena itu, seseorang yang ingin memasuki dunia ketauhidan harus lebih dahulu mengetahui secara mendalam tentang ajaran Alquran dan hadis nabi yang memuat amalan lahir, baik yang wajib maupun yang sunat.

Melaksanakan syariat haruslah didasarkan pada tata cara yang telah digariskan Alquran dan hadis nabi. Ini dilakukan hanya karena penghambaan diri terhadap adanya kecintaan terhadap Allah. Proses penghambaan diri kepada Allah karena kecintaan kepada-Nya itulah yang dimaksud dengan tarikat. Adapun hakikat berarti aspek batiniah yang dapat diartikan sebagai rahasia yang paling dalam dari amalan. Hakikat dapat juga diartikan kebenaran sejati yang mutlak sebagai akhir dari segala perjalanan hidup. Tarikat dan hakikat tidak dapat dipisahkan. Ibarat dua sisi mata uang, bahkan sambungmenyambung antara yang satu dan yang lain.

Selanjutnya, secara etimologi makrifat berarti pengetahuan atau pengenalan. Dalam istilah ketauhidan makrifat berarti pengetahuan tentang Allah melalui hati (kalbu). Pelaksanaan ajaran Islam tidak sempurna jika tidak dikerjakan secara integral tentang empat hal, syariat, tarikat, hakikat, dan makrifat. Syariat berarti peraturan; tarikat merupakan pelaksanaan; hakikat merupakan keadaan; dan makrifat merupakan tujuan, yaitu pengenalan Tuhan yang sebenar-benarnya.

Menurut Immadudin Khalil (dalam Hasan, 2003:6), fungsi sastra yang paling penting dari perspektif Islam sebagai penyebar dan penyempurna akidah tauhid, yaitu menambah keimanan seseorang dan keyakinannya untuk mengesakan Allah. Jadi, secara ringkas aspek ketuhanan ini bertolak dari konsep bahwa keindahan merupakan manifestasi kesempurnaan Allah. Dalam hal ini, karya sastra Islami adalah sastra yang segala sesuatunya harus dilakukan demi Allah yang sempurna, yang bermuara dari falsafah ketauhidan (Alquran dan hadis nabi) yang di dalamnya berisi sifat Allah (kamal, jamal, jalal), rukun iman, akidah (syariat, tarikat, hakikat, makrifat), dan asmaul husna. Intinya, dalam karya sastra islami, semua itu dimaksudkan untuk menambah keimanan dan keyakinan serta mengesakan Allah yang berwujud dalam ucapan laa ilaa ha illallah, artinya tiada Tuhan selain Allah.

Dengan demikian, teori takmilah merupakan teori sastra Islam yang di dalamnya mengandung ajaran tasawuf. Dalam penelitian ini, digunakan teori takmilah untuk mengungkapkan makna sebuah puisi yang berkaitan dengan ajaran tasawuf, yakni puisi "Idul Fitri" karya Sutardji Calzoum Bachri.

\section{HASIL DAN PEMBAHASAN}

\author{
IDULFITRI \\ (Puisi karya Sutardji Calzoum Bachri) \\ Lihat \\ Pedang taubat ini menebas-nebas hati \\ Dari masa lampau yang lalai dan sia-sia \\ Telah kulaksanakan puasa Ramadhanku \\ Telah kutegakkan shalat malam \\ Telah kuuntai wirid tiap malam dan siang \\ Telah kuhamparkan sajadahku \\ Yang tak hanya nuju ka'bah \\ Tapi ikhlas mencapai hati dan darah \\ Dan di malam Qadar aku pun menunggu \\ Namun tak bersua Jibril atau malaikat lainnya \\ Maka aku girang-girangkan hatiku \\ Aku bilang. \\ Tardji, rindu yang kau wudhukkan setiap malam
}


Belumlah cukup untuk menggerakkan Dia datang

Namun si bandel Tardji ini sekali merindu

Takkan pernah melupa

Takkan kulupa janjiNya

Bagi yang merindu insya -Allah ka nada mustajab cinta

Maka walau tak jumpa denganNya

Shalat dan zikir yang telah membasuh jiwaku ini

Semakin mendekatkan aku padaNya

Dan semakin dekat

Semakin terasa kesiasiaan pada usia lama yang lalai berlupa

O lihat Tuhan, kini si bekas pemabuk ini

Ngebut

Di jalan lurus

Jangan Kau depakkan lagi aku ke trotoir

Tempat usai lalaiku menenggak arak di warung dunia

Kini biarkan aku menenggak arak cahayaMu

Di ujung sisa usia

O usia lalai yang berkepanjangan

Yang menyebabkan aku kini ngebut di jalan lurus

Tuhan jangan Kau depakkan lagi aku di trotoir

Tempat dulu aku menenggak arak di warung dunia

Maka pagi ini

Kukenakan zirah la ilaha illallah

Aku pakai sepatu siratul mustaqiem

Akupun lurus menuju lapangan tempat shalat ied

Aku bawa masjid dalam diriku

Kuhamparkan di lapangan

Kutegakkan shalat

Dan kurayakan kelahiran kembali

Di sana

1987

Sebagaimana telah dijelaskan dalam uraian kerangka teoretis, untuk menelaah puisi "Idul Fitri" peneliti menggunakan teori takmilah, yakni teori yang menekankan aspek ketuhanan yang di dalamnya mengandung unsur keimanan, sifat Allah, syariat, tarikat, hakikat, dan makrifat.

Tarikat adalah suatu jalan atau cara untuk mendekatkan diri kepada Tuhan, sedangkan makrifat adalah tujuan untuk mengenal Tuhan secara mendalam dengan sungguh-sungguh. Dengan istilah lain, tarikat dan makrifat identik dengan sufi atau tasawuf. Pemaknaan puisi "Idul Fitri" dengan takmilah sama dengan pemaknaan dengan tasawuf.

Pemaknaan tasawuf dalam puisi tersebut dapat ditelaah berdasarkan dua hal. Pertama, dari praktikpraktik keagamaan yang dirumuskan oleh para guru sufi untuk mengantarkan manusia dalam berproses menuju penyempurnaan diri (tarikat). Kedua, cara memandang realitas secara intuitif dan irasional (makrifat).

Pada bagian pertama ini tasawuf membicarakan perjalanan yang harus ditempuh (suluk) oleh orang yang sedang berjalan menuju Tuhan (salik). Hal ini harus ditempuh sebagai tahap yang harus dilewati (maqam). Keadaan jiwa juga harus diperoleh selama dalam perjalanan (hal). Sementara itu, pemaknaan tasawuf pada bagian kedua merupakan suatu bentuk kesadaran yang tidak materialistis dan tidak empiris. Tasawuf ini dapat diartikan sebagai metode untuk menghayati kenyataan dan kesadaran keagamaan (Rahmat, 1986:261-262).

Berdasarkan teori takmilah, puisi "Idul Fitri" karya Sutardji diungkap dan digambarkan kandungan ajaran ketuhanannya. Puisi "Idul Fitri" berisikan tafakur dan muhasabah kepada Tuhan. Hal ini dapat dilihat pada bait ketiga larik ketiga, yakni "semakin mendekatkan aku padaNya".

Dugaan bahwa puisi itu termasuk puisi berdimensi ketuhanan atau sufistik diperkuat oleh judul puisi tersebut. Kata "Idul Fitri" dalam puisi itu melambangkan refleksi, yang dalam istilah tasawuf disebut tafakur. Kata tersebut juga melambangkan pemeriksaan diri, introspeksi, atau dalam bahasa tasawuf disebut muhasabah. Dalam praktiknya muhasabah itu dapat dilakukan dengan tobat.

Dengan pengetahuan yang telah dicapainya itu, seorang salik (penempuh jalan tasawuf) akan menjadi sadar dan insaf. Kesadaran itu membawanya untuk melakukan tobat. Tobat merupakan salah satu tahap dan keadaan rohani yang penting dalam tasawuf. Seorang yang bertasawuf harus bertobat supaya mendapatkan taufik dari Tuhan. Dengan adanya dosadosa yang diperbuat, seorang sufi akan merasa sulit untuk taat kepada Tuhan sehingga merasa malas untuk beribadah. Dengan demikian, tobat diperlukan agar taat beribadah. Ketaatan beribadah orang sufi yang saleh akan diterima oleh Tuhan, sedangkan ketaatan beribadah orang yang berdosa tidak akan diterima Tuhan. Tobat adalah pekerjaan hati sehingga hati perlu dibersihkan agar terhindar dari perbuatan dosa. 
Menurut ajaran ketuhanan, ada tiga macam dosa. Pertama, dosa ketika meninggalkan kewajiban, seperti halnya tidak melaksanakan salat, tidak berpuasa di bulan Ramadan, dan tidak mau mengeluarkan zakat. Kedua, dosa langsung terhadap Tuhan seperti suka minum-minuman keras dan suka makan uang riba. Ketiga, dosa terhadap sesama manusia, seperti suka menyakiti orang dan berbuat jahat. Dalam ajaran ketuhanan atau tasawuf, dosa-dosa itu tidak boleh dibiarkan, tetapi harus segera bertobat. Jika dibiarkan, dosa terus bertambah dan akan menimbulkan kerasnya hati. Hati yang keras akan sulit menerima kebenaran. Untuk itu, dalam ajaran tasawuf diwajibkan agar segera bertobat. Sekecil apa pun perbuatan dosa harus segera bertobat, yaitu dengan cara membersihkan hati dan bertekad untuk tidak mengulangi perbuatan dosa itu lagi. Hal ini tampak dalam bait ke-5 dalam puisi "Idul Fitri" seperti di bawah ini.

O usia lalai yang berkepanjangan

Yang menyebabkan aku kini ngebut di jalan lurus

Tuhan jangan Kau depakkan lagi aku di trotoir

Tempat dulu aku menenggak arak di warung dunia

Dari larik-larik puisi tersebut, tampak si aku lirik mengajak untuk segera bertobat. Bahkan, dalam puisi tersebut ditegaskan bahwa dengan "Tuhan jangan Kau depakkan lagi aku di trotoir" yang menggambarkan tidak ada waktu lagi untuk membiarkan dosa itu menumpuk. Selanjutnya diperkuat dengan larik "Tempat dulu aku menenggak arak di warung dunia" yang menjelaskan agar seseorang segera bertafakur dan muhasabah agar hati selalu bersih dan secepatnya bertobat, seperti tampak dalam larik "Yang menyebabkan aku kini ngebut di jalan lurus". Dengan demikian, makna dari larik-larik puisi itu menjelaskan bahwa bagi para sufi, tidak hanya bertobat dari segala dosa, tetapi harus dapat menghindari hal yang tidak bermanfaat, tidak berguna, dan sia-sia.

Dalam ajaran ketuhanan atau tasawuf, selain harus bertobat, juga harus selalu rindu kepada Tuhan. Biasanya seseorang akan merindukan sesuatu jika sesuatu itu sudah dikenal, dekat, dan selalu diingat. Seseorang tidak akan merasakan rindu apabila belum pernah kenal, belum pernah dekat, dan belum diketahui kualitasnya. Begitu juga dengan ketuhanan, seseorang tidak akan pernah merindukan Tuhan jika seseorang itu tidak mengenal dan dekat dengan Tuhan. Untuk merindukan Tuhan, bagi orang-orang sufi harus makrifat dan harus dapat membuka tirai yang menutupi dirinya. Sebab, tidak jarang kemewahan hidup di dunia akan menjadi penghalang dalam mendekatkan diri kepada Tuhan.

Dalam ajaran tasawuf, mendekatkan diri kepada Tuhan bertujuan agar selalu rindu kepada Tuhan. Dengan jalan (tarikat), hati harus selalu risau memikirkan diri takut berbuat salah. Dengan hati risau akan timbul kerinduan terhadap Tuhan. Dengan kata lain, orang sufi senantiasa rindu kepada Tuhan. Rindu karena keindahan, kebesaran, kemuliaan dan kesempurnaan Tuhan. Rindu semacam ini merupakan rindu yang didambakan oleh orang-orang sufi. Sebab, hanya dengan selalu merindukan Tuhan, rahasiarahasia ketuhanan akan terbuka sehingga akan semakin menikmati hidup apa adanya. Rasa rindu kepada Tuhan tidak akan datang jika tidak memiliki rasa cinta kepada Tuhan.

Sebagaimana dalam puisi "Idul Fitri" bait ke-2, dalam larik ke-8, "bagi yang merindu akan ada mustajab cinta". Maksudnya, rindu hanya akan ada dengan adanya cinta. Demikian pula, rindu hanya akan terpuaskan oleh adanya cinta. Cinta laksana obat yang mustajab dalam menyembuhkan penyakit dan memuaskan rasa rindu, seperti tampak dalam bait ke-2 dalam puisi "Idul Fitri" sebagai berikut.

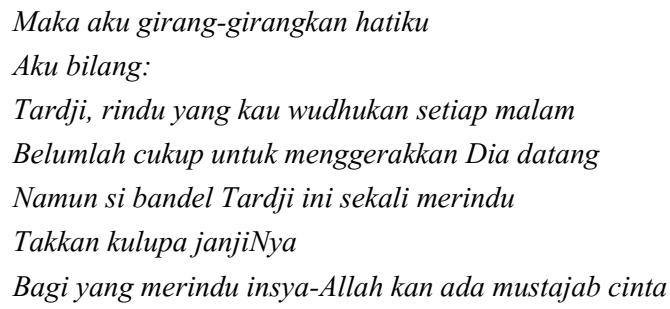

Dalam larik-larik puisi itu juga terdapat makna cinta kepada ketuhanan, yaitu "bagi yang merindu insya-Allah kan ada mustajab cinta". Dalam ketuhanan cinta adalah tema populer dalam dunia tasawuf. Para sufi, seperti Al-Ghazali, Jalaludin Rumi, Fariduddin Attar, Suharwadi, dan Rabiatul Adawiyah, banyak berbicara tentang masalah cinta. Cinta, secara sederhana dapat dirumuskan sebagai kecenderungan terhadap sesuatu yang indah dan menarik sehingga membuat si pecinta mabuk kepayang, mengalami ekstase atau fana (senyap, sirna, dan menyatu dalam 
keindahan). Menurut Al-Ghazali (1960:7) dalam kitabnya Cinta dan Bahagia, cinta itu terbagi dalam lima macam, yaitu sebagai berikut.

1) Cinta pada wujud, yaitu cinta kesempurnaan dalam diri sendiri.

2) Cinta seseorang kepada seseorang yang berbuat baik kepadanya.

3) Cinta kepada yang berbuat baik karena zatnya, dari segi substansinya meskipun kebaikannya itu ditujukan kepada yang lain.

4) Cinta pada yang bagus, indah, elok, baik lahir maupun batin.

5) Cinta karena adanya tanasub (persesuaian) batin.

Dengan demikian, setiap yang indah itu pasti akan dicintai, tetapi yang benar-benar indah secara mutlak hanyalah ada satu cinta, yaitu cinta kepada Tuhan. Kesempurnaan cinta itu dapat dicapai karena adanya persesuaian antara dirinya dan Tuhan. Menurut ajaran tasawuf, orang yang akan bahagia di akhirat adalah orang yang paling kuat cintanya kepada Tuhan. Hal ini disebabkan akhirat merupakan suatu tempat yang sangat dirindukan bagi orang-orang sufi. Betapa besar nikmat si pecinta jika telah lama menahan rindu, kemudian berjumpa dengan yang dicintainya. Semakin kuat cintanya, semakin besar pula nikmat yang akan didapatnya. Itulah ajaran tasawuf dalam cinta kepada Tuhan, seperti yang tergambar dalam puisi "Idul Fitri”" tersebut.

Dalam ajaran tasawuf, setelah orang melaksanakan tobat dan cinta kepada Tuhan, cahaya kebenaran pun akan datang dari Tuhan. Hal ini seperti tergambar dalam bait ke-4, larik ke-6, "Kini biarkan aku menenggak arak cahayaMu".

Dalam tradisi tasawuf, kata cahaya digunakan untuk merujuk berbagai hal. Cahaya merupakan sebutan sesuatu yang tampak dengan sendirinya ataupun yang membuat tampak benda lainnya, seperti cahaya matahari. Cahaya juga berarti mata lahiriah (indrawi) karena memiliki daya serap. Dengan daya itu, perserapan akan terwujud. Mata hati, akal, roh, atau jiwa disebut juga sebagai cahaya. Jika mata indrawi membutuhkan cahaya matahari, mata hati atau akal membutuhkan cahaya kitab suci, seperti Alquran adalah cahaya langsung dari Tuhan. Tuhan adalah cahaya di atas cahaya, yaitu cahaya langit dan bumi, cahaya tertinggi dan terakhir, dan cahaya yang sebenar-benarnya dan hakiki. Cahaya juga berarti wujud, sesuatu yang berwujud dengan sebenarbenarnya adalah Tuhan. Sebutan cahaya selain Tuhan, hanyalah kiasan, tak ada wujud sebenarnya. Seperti tampak dalam puisi "Idul Fitri" dalam larik "kini biarkan aku menenggak arak cahayaMu".

Dengan melaksanakan tobat yang sungguh-sunguh dan mengutamakan cinta kepada Tuhan, akan datang cahaya dari Tuhan bagi seorang sufi. Kemudian langkah berikutnya bagi seorang sufi adalah tafakur. Tafakur adalah suatu jalan untuk mengenal dan mendekatkan diri kepada Tuhan sebagaimana salah satu hadis nabi yang artinya "Siapa yang mengenal dirinya, akan mengenal Tuhannya".

Untuk mengenal Tuhannya, terlebih dahulu mengenal dirinya sendiri, sebagaimana digambarkan dalam bait ketiga dalam larik ketiga, "Semakin mendekatkan aku padaNya". Larik tersebut bermakna menafakuri diri; apakah diri sudah bersih atau masih kotor. Selanjutnya, pada larik keempat, "dan semakin dekat" dan pada bait kelima dalam larik, "semakin terasa kesiasiaan pada usia lama yang lalai berlupa" menggambarkan bahwa diri ini termasuk diri yang kotor.

Bagi kaum sufi, kalbu merupakan inti dari segala sumber yang menggerakkan jiwa dan badannya, yang sepenuhnya digunakan untuk mendekatkan diri dan mengabdi kepada Tuhan. Dalam bahasa ketuhanan, apabila kalbunya bersih, segala tindakan dan perilakunya akan baik pula. Sebaliknya, jika kalbunya kotor, tindakan dan perilakunya juga tidak akan baik.

Selain itu, yang menandai dan memperkuat bahwa puisi "Idul Fitri" termasuk puisi ketuhanan atau tasawuf adalah adanya kata zikir. Kata zikir sering dipakai sebagai sinonim kata wirid, tetapi sebenarnya kata wirid lebih bersifat umum. Pengertian zikir lebih luas dan mencakup wirid itu sendiri. Zikir ada dua macam, yaitu zikir lisan dan zikir kalbu. Zikir lisan adalah zikir dengan mengucapkan lafal-lafal zikir tertentu, baik dengan suara yang keras maupun dengan suara yang hanya dapat didengar oleh orang yang berzikir itu sendiri. Ada sejumlah lafal zikir yang sudah baku yang bersumber dari Alquran ataupun yang disebutkan dalam hadis nabi, di antaranya tahmid, tasbih, takbir, tahlil, istigfar dan lafal zikir berupa ayat-ayat Alquran. Adapun zikir 
kalbu disebut juga zikir tersembunyi, yakni zikir yang tersembunyi di dalam hati, tanpa ada suara dan katakata. Zikir kalbu hanya memenuhi kalbu, seirama dengan detak jantung dan mengikuti keluar masuknya nafas. Keluar masuknya nafas yang diiringi dengan kesadaran akan kehadiran Tuhan merupakan pertanda bahwa kalbu itu hidup dan berkomunikasi langsung dengan Tuhan (Ismail, 2003:172-176).

Dalam pengertian luas, zikir bukan hanya ucapan zikir saja, melainkan juga termasuk salat dan tobat, bahkan meliputi segala tindakan apabila kita merasa selalu diawasi oleh Tuhan. Oleh karena itu, bagi orang-orang sufi, berzikir, salat, dan tobat selalu dilakukan dalam setiap keadaan, sebagaimana dalam puisi "Idul Fitri" dalam bait ketiga larik kedua, "shalat dan zikir yang telah membasuh jiwaku ini". Kata zikir dan shalat dalam puisi tersebut bermakna memperteguh dan mendekatkan diri kepada Tuhan. Bagi kaum sufi, hal demikian itu merupakan jalan untuk bertafakur dengan mendekatkan diri kepada Tuhan, sebagaimana dalam bait ketiga, larik ketiga, "semakin mendekatkan aku padaNya".

Dalam puisi "Idul Fitri” melalui kata-kata seperti zikir dan salat, manusia diajak untuk meningkatkan keimanan atau ketuhanan. Namun, dalam puisi tersebut digambarkan juga bahwa ketuhanan seseorang dipertanyakan eksistensinya, sebagaimana terlukis dalam bait kelima berikut ini.

O usia lalai yang berkepanjangan

Yang menyebabkan aku kini ngebut di jalan lurus

Tuhan jangan Kau depakkan alagi aku di trotoir

Tempat dulu aku menenggak arak di warung dunia

Selain mengandung makna tafakur, puisi "Idul Fitri" juga mengandung makna muhasabah yang berarti melakukan perhitungan baik dan buruk terhadap perbuatan yang sudah kita lakukan. Bila kita lebih banyak melakukan kebaikan, kita bersyukur dan berusaha meningkatkannya lagi, atau paling tidak mempertahankannya (Adam, 2003:116). Pemeriksaan diri berkaitan dengan upaya dalam menjaga kalbu, lidah, mata, dan segenap anggota badan agar terhindar dari perbuatan jelek sehingga akan terhindar dari api neraka. Langkah selanjutnya adalah mengevaluasi semua hal yang terlintas agar selalu berpikir positif.

Setiap tindakan dan pikiran kita didasarkan pada dorongan ilahiah dan bukan dorongan setan. Biasanya pada malam hari para sufi selalu bermuhasabah. Hal ini dapat ditelaah dalam bait keempat larik kelima, "perhatikan zuhudnya". Dengan menggunakan istilah para sufi, zuhud mengantarkan kita pada alam mukasyafah. Orang zuhud tidak bersedih karena kemiskinan atau diberi penyakit. Apabila mereka ditakdirkan menjadi orang kaya, mereka tidak akan kikir dan tidak bersuka ria, tetapi mereka akan menjadi orang yang pandai bersyukur atas nikmat itu. Mereka menikmati hidup dengan apa yang telah diberikan oleh Tuhannya, dengan apa adanya tanpa harus menggerutu. Kehidupan mereka dihiasi dengan keikhlasan dan ketulusan hati dalam menerima hidup. Mereka selalu mengambil hikmah di balik kehidupan. Dengan kata lain, zuhud berada di dunia, tetapi tidak mendunia; zuhud tidak meninggalkan dunia, tetapi tidak pula meletakkan hatinya untuk dunia, seperti terlukis dalam larik-larik dalam bait pertama dalam puisi "Idul Fitri”" berikut ini.

Lihat
Pedang taubat ini menebas-nebas hati
Dari masa lampau yang lalai dan sia-sia
Telah kulaksanakan puasa Ramadhanku
Telah kutegakkan shalat malam
Telah kuuntai wirid tiap malam dan siang
Telah kuhamparkan sajadahku
Yang tak hanya nuju ka'bah
Tapi ikhlas mencapai hati dan darah
Dan di malam Qadar aku pun menunggu
Namun tak bersua Jibril atau malaikat lainnya

Dengan kezuhudannya, seorang sufi hidup dengan sederhana dan meninggalkan kemewahan dunia. Dalam hidupnya, seorang sufi mementingkan kebahagiaan akhirat dengan jalan bertobat dan melaksanakan ibadah kepada Tuhan. Dalam bait pertama puisi "Idul Fitri" digambarkan kezuhudan seorang ahli tasawuf, seperti dalam larik kedua, "pedang taubat ini menebas-nebas hati”. Larik ini menggambarkan seorang tasawuf tidak berhenti minta ampunan atau bertobat dengan sesungguhnya kepada Tuhan.

Larik keempat "telah kulaksanakan puasa Ramadhanku" melukiskan amalan puasa di bulan Ramadan, sedangkan larik kelima, "telah kuteggakkan shalat malam" merupakan pendekatan kepada Tuhan dengan salat tahajud. Dengan salat di malam hari, saat 
orang lain tidur pulas, seorang sufi merasa lebih dekat dengan Tuhan.

Larik kesembilan, "tapi ikhlas mencapai hati dan darah" bermakna keikhlasan yang betul-betul ikhlas terhadap apa yang dimiliki yang datangnya dari Tuhan. Dengan keikhlasan ini, seorang sufi merasa tentram dan bahagia dalam hidupnya. Hal ini diperkuat dalam larik kesepuluh, "dan di malam Qadar aku pun menunggu", yaitu malam yang lebih baik dari seribu bulan; suatu malam yang diperuntukkan bagi orang-orang yang ikhlas dan mengabdi kepada TuhanNya secara benar. Dengan demikian, kebahagiaan pun tercapai, baik bahagia di dunia maupun bahagia di akhirat nanti. Itulah gambaran makna tasawuf yang terdapat dalam puisi "Idul Fitri" karya Sutardji Calzoum Bachri yang ditelaah berdasarkan teori takmilah.

\section{PENUTUP}

Penelaahan puisi "Idul Fitri" karya Sutardji Calzoum Bachri dengan menggunakan pendekatan teori takmilah dari aspek ketuhanan (kamal) menggambarkan bahwa puisi tersebut bernuansa ketuhanan yang berdimensi sufistik. Puisi sufistik mengungkap dan menggambarkan perenungan diri terhadap eksistensi diri dengan Tuhannya. Hal tersebut diperkuat dengan adanya kata-kata cahaya, cinta, salat, zikir, dan taubat. Dalam istilah ketuhanan atau tasawuf, kata-kata itu disebut dengan tafakur dan muhasabah. Dengan tafakur dan muhasabah, diharapkan datang cahaya Tuhan. Dalam bahasa ketuhanan, cahaya disebut nur ilahiah, artinya cahaya yang datang dari Tuhan, seperti tampak dalam larik keenam pada bait keempat, "Kini biarkan aku menenggak arak cahayaMu".

Dengan demikain, puisi "Idul Fitri" karya Sutardji Calzoum Bachri ini sangat relevan ditelaah dengan menggunakan teori takmilah. Hal ini disebabkan dalam puisi tersebut digambarkan tentang ketuhanan yang berkaitan dengan ajaran tasawuf.

\section{DAFTAR PUSTAKA}

Adam, Muchtar. 2003. "Muqarobah: Merasakan Kehadiran Allah," dalam Qamaruddin S.F. (ed.) Zikri Sufi. Jakarta: Serambi.

Al-Ghazali. 1960. Cinta dan Bahagia. Diterjemahkan oleh Abdullah bin Nuh. Jakarta: Tintamas.

Bakar, Shafei Abu. 1996. Takmilah: Teori, Falsafah dan Prinsip. Dewan Sastera. Kuala Lumpur: Dewan Bahasa dan Pustaka.

Bakar, Shafei Abu. 2000. "Nilai dan Sastera dalam Teori Takmilah," kertas kerja yang dibentangkan dalam "Seminar Teori Sastera Islam: Kaedah dan Penerapannya, Anjuran Bahagian Teori dan Kritikan Sastera." Dewan Bahasa dan Pustaka, Kuala Lumpur, di Hotel Renaissance Palm Garden, Putrajaya pada 26-28 September.

Braginsky, V.I. 1993. Tasawuf dan Sastra Melayu: Kajian dan Teks-Teks. Jakarta: RUL.

Bachri, Sutardji Calzoum. 1987. "Sastra Transedental," dalam Harian Pelita, Rabu, 21 Oktober 1987, hlm. V. 1991. "Rubrik Sajak," dalam Horison, Maret 1991.

2002. O, Amuk, Kapak. Jakarta: Yayasan Indonesia dan Majalah Horison.

Budiman, Arief. 1979. Chairil Anwar: Sebuah Pertemuan. Jakarta: Pustaka Jaya.

Hasan, Mohamad Mokhtar. 2003. "Ketakmilah dalam Puisi Anbiya", kertas kerja yang dibentangkan dalam "Seminar Teori Sastra Islam: Kaedah dan Penerapannya, Anjuran Bahagian Teori dan Kritikan Sastera." Dewan Bahasa dan Pustaka, Kuala Lumpur, di Hotel Renaissance Palm Garden, Putrajaya pada 26-28 September.

Ismail, Asep Usman. 2003. "Dzikrullah: Membeningkan Hati, Menghampiri Ilahi” dalam Qamaruddin S.F. (ed.), Zikir Sufi. Jakarta: Serambi. 
Asep Supriadi: Memahami Puisi "Idul Fitri” dengan Teori Takmilah

Mangunwijaya, Y.B. 1982. Sastra dan Religiositas. Jakarta: Sinar Harapan.

Nasution, Harun. 1986. Teologi Islam: Aliran-Aliran Sejarah Analisa Perbandingan. Jakarta: UI Press.

Nurgiyantoro, Burhan. 2002. Teori Pengkajian Fiksi. Yogyakarta: Gajahmada University Press.

Rahmat, Jalaludidin. 1986. Islam Alternatif: Ceramah-Ceramah di Kampus. Bandung: Mizan.

Rosa, Helvy Tiana. 2003. Segenggam Gumam. Bandung: PT Syaamil Cipta Media

Santoso, Puji dkk. 2004. Sastra Keagaman dalam perkembangan Sastra Indonesia: Puisi 1946-1965. Jakarta: Pusat Bahasa, Departemen Pendidikan Nasional.

Sitanggang, dkk. 2003. Religiusitas dalam Tiga Novel Modern: Kemarau, Khotbah di Atas Bukit, dan Kubah. Jakarta: Pusat Bahasa, Departemen Pendidikan Nasional.

Sikana, Mana. 2005. Teori dan Kritikan Sastra Malaysia dan Singapura. Singapura: Pustaka Karya.

Schimmel, Annemarie. 1981. Mystical Dimensions of Islam. Chapel Hill: The University of Nort Carolina Press.

Tasai, Amran S. dan Djamari. 2003. Pandangan Sastrawan AA Navis dan Tanggapan Kritikus Terhadap Karyanya. Jakarta: Pusat Bahasa, Departemen Pendidikan Nasional. 